\title{
O QUE É UMA ESCOLA JUSTA?
}

\author{
FRANÇOIS DUBET \\ École des Hautes Études en Sciences Sociales - Cadis \\ Université Victor Segalen 2 - Bordeaux \\ francois.dube@sociologie.u-bordeaux2.fr \\ Tradução: Édi Gonçalves de Oliveira e Sérgio Cataldi
}

\begin{abstract}
RESUMO
São bastante complexos os conceitos de igualdade e de justiça escolar que informam as politicas compensatórias. Este tex to busca elucidá-los com o fito de contribuir para entender o sentido e o alcance das politicas de educação.

DEMOCRATIZAÇÃO DAEDUCAÇÃO-IGUALDADE-POLITICASPÚBLICAS-POLITIICAS COMPENSATÓRAS
\end{abstract}

\section{ABSTRACT}

WHAT IS A FAIR SCHOOL? The concepts of school equality and justice that inform the compensatory policies are very complex. This text tries to elucidate them, aiming to contribute to understanding the meaning and the extent of educational policies.

DEMOCRATIZATION OF EDUCATION - EQUALITY - PUBLIC POLICIES COMPENSATORY POLICIES 
Como visam a produzir maior justiça escolar, não podemos deixar de ser muito favoráveis às medidas compensatórias e paliativas. Isto posto, os conceitos de igualdade e de justiça escolar que comandam essas práticas não são tão claros quanto poderia parecer à primeira vista e é importante refletir sobre a justiça escolar para avaliar o sentido e o alcance das políticas escolares. A priori, o desejo de justiça escolar é indiscutível, mas a definição do que seria uma escola justa é das mais complexas, ou mesmo das mais ambíguas, pois podemos definir justiça de diferentes maneiras. Por exemplo, a escola justa deve:

- Ser puramente meritocrática, com uma competição escolar justa entre alunos social e individualmente desiguais?

- Compensar as desigualdades sociais, dando mais aos que têm menos, rompendo assim com o que seria uma rígida igualdade?

- Garantir a todos os alunos um mínimo de conhecimentos e competências?

- Preocupar-se principalmente com a integração de todos os alunos na sociedade e com a utilidade de sua formação?

- Tentar fazer com que as desigualdades escolares não tenham demasiadas conseqüências sobre as desigualdades sociais?

- Permitir que cada um desenvolva seus talentos específicos, independentemente de seu desempenho escolar?

Cada um de nós acredita que a escola justa deve ser tudo isso ao mesmo tempo, que ela deve responder a todas essas concepções de justiça. $\bigcirc$ problema surge do fato de esta afirmação ser uma pura petição de princípios, pois cada uma das concepções de justiça evocadas entra imediatamente em contradição com as outras. Assim, uma meritocracia escolar justa não garante a diminuição das desigualdades; a preocupação com a integração social dos alunos tem grande probabilidade de confirmar seu destino social; a busca de um mínimo comum arrisca-se a limitar a expressão dos talentos; uma escola preocupada com a singularidade dos indivíduos age contra a cultura comum que uma escola deve transmitir e que também é uma forma de justiça... Portanto, não existe solução perfeita, mas uma combinação de escolhas e respostas necessariamente limitadas. Este texto busca antes colocar os problemas do que oferecer respostas. Sua ambição é afastar-nos das petições de princípios, que fazem bem à alma mas que, na realidade, tendem a evitar os problemas em vez de evidenciá-los. 


\section{A IGUALDADE DE OPORTUNIDADES E SEUS LIMITES}

Ao contrário das sociedades aristocráticas que priorizavam o nascimento e não o mérito, as sociedades democráticas escolheram convictamente o mérito como um princípio essencial de justiça: a escola é justa porque cada um pode obter sucesso nela em função de seu trabalho e de suas qualidades.

Sabemos que a escolha da igualdade de oportunidades sempre foi limitada e que, nas sociedades mais desenvolvidas, até a década de 1960, o nascimento continuava a pesar consideravelmente na orientação escolar dos alunos nos sistemas divididos em várias escolas: a escola do povo, a escola das classes médias, a escola da burguesia, as escolas profissionais, as da cidade, as do campo, as da Igreja, as do Estado. E isso ainda ocorre na maioria dos países em desenvolvimento. Na verdade, durante muito tempo, o mérito desempenhava um papel apenas marginal para os filhos dos trabalhadores e os "dotados" que podiam, graças ao sistema de bolsas, ter acesso ao antigo ginásio e, para uma minoria deles, chegar ao colegial. Mas, basicamente, cada categoria social estava vinculada a um determinado tipo de público escolar. Na verdade, a questão não era tanto criar um reino de igualdade de oportunidades, e sim permitir uma certa mobilidade social graças à escola para as classes médias e uma minoria do povo. Esse elitismo republicano (é assim que ele é chamado na França) repousa, portanto, sobre um princípio de mérito bastante parcial, e o fato de que muitos professores tenham sido bolsistas não nos deve levar a uma nostalgia que não se sustenta além das classes médias escolarizadas, que tudo devem à escola.

A igualdade de oportunidades meritocrática supõe igualdade de acesso. Nos países ricos e modernos, o princípio meritocrático da igualdade de oportunidades foi progressivamente implantado com o alongamento da escolaridade obrigatória comum e considerável abertura do ensino secundário e superior: na França, por exemplo, quase 100\% dos alunos freqüentam o ensino fundamental; quase $70 \%$ obtêm o certificado de conclusão do ensino médio e mais de $70 \%$ de uma coorte etária está escolarizada aos 20 anos. Dito de outro modo, a igualdade de acesso à escola está quase garantida e constitui um progresso considerável. Contudo, essa escola não se tornou mais justa porque reduziu a diferença quanto aos resultados favoráveis entre as categorias sociais e sim porque permitiu que todos os alunos entrassem na mesma competição. Do ponto de vista formal, atualmente todos os alunos podem visar à excelên- 
cia, na medida em que todos podem, em princípio, entrar nas áreas de maior prestígio, desde que autorizados por seus resultados escolares. A escola é gratuita, os exames são objetivos e todos podem tentar a sorte. $\bigcirc$ quadro formal da igualdade de oportunidades e do mérito foi globalmente instalado em um grande número de países.

Porém, esta concepção puramente meritocrática da justiça escolar se defronta com grandes dificuldades e, mesmo que aceitemos o princípio, fica claro que ele deve ser ponderado. Quais são essas dificuldades?

I. Fundamentalmente a Sociologia da Educação mostra que a abertura de um espaço de competição escolar objetiva não elimina as desigualdades. Primeiro as desigualdades entre as pessoas, pois, desde a escola elementar, as diferenças de desempenho entre alunos que pertencem às mesmas categorias sociais são evidentes. Depois, as desigualdades entre os sexos e entre os grupos sociais persistem e, desde o início, os mais favorecidos têm vantagens decisivas. Essas desigualdades estão ligadas às condições sociais dos pais, mas também ao seu envolvimento com a educação, ao apoio que dão aos filhos, bem como à sua competência para acompanhá-los e orientá-los. Afinal, embora a escola meritocrática de massas tenha elevado o nível de escolarização de toda a população e, na França, o número dos que terminam o colegial tenha sido multiplicado por dez nos últimos cinqüenta anos, as diferenças entre os grupos não foram sensivelmente reduzidas durante esse mesmo período. É preciso dizer claramente: esse modelo gerou decepção. E a mesma constatação se impõe, com algumas variantes, em todas as áreas, e todas as teorias sociológicas dão sua contribuição para explicar esse fenômeno: habitus de classe, contextos diferentes de racionalidade das escolhas, mobilização desigual das famílias. Em resumo, as desigualdades sociais pesam muito nas desigualdades escolares.

2. O modelo de igualdade de oportunidades meritocrático pressupõe, para ser justo, uma oferta escolar perfeitamente igual e objetiva, ignorando as desigualdades sociais dos alunos. Ora, todas as pesquisas mostram que a escola trata menos bem os alunos menos favorecidos: os entraves são mais rígidos para os mais pobres, a estabilidade das equipes docentes é menor nos bairros difíceis, a expectativa dos professores é menos favorável às famílias desfavorecidas, que se mostram mais ausentes e menos informadas nas reuniões de orientação... A imagem extrema dessa situação é a do tratamento reservado aos alunos dos estabelecimentos de elite, públicos ou privados, que oferecem aos 
bons alunos, muitas vezes socialmente privilegiados, numerosos cursos, com grupos reduzidos e professores motivados e experientes. Em contrapartida, os primeiros ciclos das universidades acolhem os alunos menos bons e menos privilegiados em anfiteatros abarrotados em que os cursos são mais diluídos e às vezes menos valorizados. O modelo meritocrático está longe, portanto, de sua realização; a competição não é perfeitamente justa. Em uma palavra: quanto mais favorecido o meio do qual o aluno se origina, maior sua probabilidade de ser um bom aluno, quanto mais ele for um bom aluno, maior será sua possibilidade de aceder a uma educação melhor, mais diplomas ele obterá e mais ele será favorecido...

3. Também é importante sublinhar uma certa crueldade do modelo meritocrático. Na verdade, quando adotamos o ideal de competição justa e formalmente pura, os "vencidos", os alunos que fracassam, não são mais vistos como vítimas de uma injustiça social e sim como responsáveis por seu fracasso, pois a escola lhes deu, a priori, todas as chances para ter sucesso como os outros. A partir daí, esses alunos tendem a perder sua auto-estima, sendo afetados por seu fracasso e, como reação, podem recusar a escola, perder a motivação e tornar-se violentos. A seu ver, a escola meritocrática atraiu-os para uma competição da qual foram excluídos; eles acreditaram na vitória e na igualdade de oportunidades e descobrem suas fraquezas, sem o consolo de poder atribuir o fato às desigualdades sociais, das quais não são mais diretamente vítimas. Do ponto de vista dos professores, a escola meritocrática também é cruel, pois a escola se torna o principal agente de seleção escolar e social, tomando as decisões de orientação que a sociedade abdica de tomar, na contracorrente da escolaridade. Assim, e independentemente do que pensam os atores, a escola meritocrática legitima as desigualdades sociais.

4. O modelo de igualdade de oportunidades implica sérios problemas pedagógicos. O princípio meritocrático pressupõe que todos os alunos estejam envolvidos na mesma competição e sejam submetidos às mesmas provas. Ora, as diferenças se aprofundam rapidamente, e alguns alunos parecem incapazes de continuar competindo. Na competição com os outros, eles perdem, se desesperam e desanimam seus professores. Deixados de lado, são marginalizados em currículos diferenciados e ficam cada vez mais enfraquecidos. No final das contas, o sistema meritocrático cria enormes desigualdades entre os alunos bons e os menos bons. Mas isso é próprio de todas as competições, mesmo que sejam justas quanto a seus princípios. 
5. Finalmente, podemos questionar a própria idéia de mérito. $\bigcirc$ mérito é outra coisa além da transformação da herança em virtude individual? Ele é outra coisa além de um modo de legitimar as desigualdades e o poder dos dirigentes? Seguindo Rawls (1987), podemos nos perguntar também se o mérito realmente existe, se ele pode ser medido objetivamente, se pode ser aplicado às crianças e até que idade. Se não somos responsáveis por nosso nascimento, como sê-lo por nossos dons e aptidões?

\section{UMA FICÇÃO NECESSÁRIA}

Contudo, não parece possível abandonar o modelo de uma justiça baseada no mérito, por razões de fundo. Em uma sociedade democrática, ou seja, em uma sociedade que em princípio postula a igualdade entre todos, o mérito pessoal é o único modo de construir desigualdades justas, isto é, desigualdades legítimas, já que as outras desigualdades, principalmente as de nascimento, seriam inaceitáveis. Portanto, é preciso construir esse sistema, tomando cuidado para que exista igualdade de oferta escolar, evitando as várias maneiras de "trapacear", pela parcialidade dos encaminhamentos à trajetórias implícitas*, pelas múltiplas exceções... Devemos impor a freqüência à escola perto de casa, ou seja, fazer a segregação por local de residência, ou é preciso proibir isso, para que cada um possa fazer sua escolha? Em qualquer caso, a situação atual é muito injusta, pois alguns podem escapar dela e outros não. É preciso principalmente assegurar a igualdade da oferta educacional para suprimir alguns "privilégios", algumas cumplicidades evidentes entre a escola e determinados grupos sociais. Essa é uma luta fundamental para a justiça escolar. Se compararmos a justiça meritocrática a uma espécie de competição esportiva, seria preciso garantir que todos os competidores conhecessem as regras do jogo, o que não é o caso da escola, em que muitas famílias as ignoram; seria preciso que o terreno fosse igual para todos, ou seja, que o sistema fosse transparente e que os juízes não fossem parciais. Ainda estamos longe disso, apesar da igualdade de oportunidades alardeada em todos os discursos.

* No ensino médio francês, os alunos, de acordo com seu desempenho, são encaminhados a cursar certos arranjos curriculares mais ou menos prestigiados socialmente, os quais facultam o acesso aos cursos universitários mais conceituados ou mesmo limitam as possibilidades ulteriores de estudo e profissionalização a opções menos valorizadas na sociedade (N. da E.). 
Também é evidente que, em muitos países, ainda estamos muito longe da igualdade de oportunidades, e que aos diferentes grupos sociais são oferecidos sistemas escolares diferentes e desiguais. Nesse caso, convém construir a igualdade de acesso. Mas não podemos perder de vista que o fator de igualdade essencial é antes de tudo a redução das próprias desigualdades sociais. Nenhuma escola consegue, sozinha, produzir uma sociedade justa.

Não nos deixemos, porém, levar por ilusões: mesmo que o modelo meritocrático seja aperfeiçoado, ele tem seus próprios limites intrínsecos e não deixará de nos desapontar, pois algumas de suas fraquezas dizem respeito à sua própria natureza e ao fato de que fatalmente produz mais vencidos do que vencedores. Portanto, é preciso procurar outros princípios de justiça para reformar esse modelo. Mas não podemos ignorar que essa igualdade de acesso supõe, na contramão da escola, uma grande redução das desigualdades sociais; nenhuma escola pode, sozinha, criar uma sociedade mais igualitária.

\section{A JUSTIÇA DISTRIBUTIVA}

O ideal meritocrático consiste em dar a mesma coisa a todos, e sabemos que, no caso da escola, estamos longe disso. Mas esta concepção de justiça será suficiente se considerarmos que as pessoas e os grupos sociais não são iguais diante da escola? Para obter mais justiça, seria preciso, portanto, que a escola levasse em conta as desigualdades reais e procurasse, em certa medida, compensá-las. Esse é o princípio da discriminação positiva.

Essa discriminação tem inicialmente um aspecto "negativo", que consiste em evitar a concentração excessiva de alunos idênticos, de guetos da cultura, do dinheiro e da qualidade, de um lado, e de guetos de pobreza e das dificuldades, do outro. Ora, sabemos perfeitamente que a escola, pública ou privada, participa de diversos mecanismos de "mercados" escolares: escolas fortes de um lado, escolas de segunda categoria do outro. A melhor maneira de resistir a esse fenômeno incompatível com uma lógica puramente igualitária é a introdução de mecanismos compensatórios eficazes e centrados nos alunos e em seu trabalho: estudos dirigidos, atividades esportivas e culturais, estabilidade e qualidade das equipes educacionais, preparação específica para concursos e exames... A justiça não consiste apenas em aliviar o trabalho dos professores nas áreas mais difíceis, e sim em tornar esse trabalho mais eficaz. 
Sabemos bem que em muitos casos a justiça consiste em ultrapassar a "igualdade pura". Se quisermos que as mulheres entrem na política, será preciso que criemos quotas; se desejarmos que os bons alunos dos bairros populares façam bons estudos, será preciso que tenham preparação específica; se quisermos que todos saibam ler, será preciso maior tempo de aprendizagem em algumas escolas; se quisermos que os alunos tenham acesso à alta cultura, será preciso organizar clubes de teatro e cinema para aqueles que têm apenas uma televisão em casa...

Ao apresentar essas idéias, talvez banais, não podemos nos calar em relação a três coisas. A primeira é que a justiça distributiva sempre se choca com forte resistência por parte daqueles aos quais o modelo meritocrático puro assegura a reprodução de vantagens, como mostra a enorme dificuldade de tocar no recrutamento das elites. A segunda é que a experiência nos ensina que esses dispositivos têm uma influência limitada e não conseguem alterar sensivelmente o jogo da produção das desigualdades escolares. A terceira é que os grupos sociais mais mal posicionados em relação à escola, e que deveriam defender esta orientação, não são os mais aptos a tomar a palavra e defendê-la. Portanto, é preciso colocar o problema da justiça em outros termos.

\section{GARANTIA DE COMPETÊNCIAS MÍNIMAS}

Uma das formas de justiça social consiste em garantir um mínimo de recursos e proteção aos mais fracos e desfavorecidos. Desse ponto de vista, um sistema justo garantiria limites mínimos abaixo dos quais ninguém deveria ficar: é o caso do salário mínimo, da assistência médica, dos benefícios elementares que protegem os mais fracos da exclusão total. Na verdade, essas garantias visam a limitar os efeitos dos sistemas meritocráticos cuja mecânica muitas vezes leva à manutenção ou mesmo acentuação das desigualdades. Essa concepção de justiça, principalmente a de Rawls, considera que a justiça de um sistema escolar pode ser medida pelo modo como trata os mais fracos e não somente pela criação de uma competição pura. Mais exatamente, ela considera que as desigualdades são aceitáveis, ou mesmo justas, quando não pioram as condições dos mais fracos.

No campo dos rendimentos, esse raciocínio nos é familiar. A maioria das 
desigualdades de salário não nos choca enquanto não provoca a degradação das posições menos favorecidas. No domínio escolar, geralmente temos muita dificuldade para pensar nesses termos e a noção de "mínimo cultural" é muitas vezes percebida como o cavalo de Tróia que traz consigo uma abdicação e um rebaixamento do nível de ensino. Entretanto, existem muitas injustiças fundamentais quando se observa, por exemplo, que na França, na sexta série (aos 12 anos de idade), os alunos que estão entre os 10\% mais fracos têm escores de desempenho três vezes piores que os alunos que estão entre os $10 \%$ meIhores ou então quando as dificuldades de leitura excluem, de um só golpe, determinados alunos de qualquer aprendizado normal. Nesse caso, o sistema justo, ou menos injusto, não é o que reduz as desigualdades entre os melhores e os mais fracos, mas o que garante aquisições e competências vistas como elementares para os alunos menos bons e menos favorecidos.

Essa afirmação de bom senso traz conseqüências práticas e causa profundas alterações nas concepções referentes à competição escolar. É importante, inicialmente, definir esse nível garantido e, mais concretamente, definir os conteúdos da cultura escolar comum, aquela que todos os alunos precisam adquirir ao final da escolaridade obrigatória. Ora, os programas não são concebidos dessa maneira. Dentro de uma lógica meritocrática que permite que todos atinjam a excelência, eles são definidos por essa excelência, isto é, pelas expectativas dos ciclos posteriores e, a partir daí, os alunos mais fracos se desgarram como os corredores de um pelotão de ciclistas em uma subida. Essa concepção da justiça implica, então, uma mudança de perspectiva: os programas da escolaridade comum e obrigatória devem ser definidos a partir das exigências comuns garantidas a todos, os melhores alunos podendo, evidentemente, aproveitá-los muito melhor e progredir mais depressa. Mas a qualidade do percurso dos melhores não levaria os outros a serem totalmente abandonados.

A definição da justiça em termos de garantias mínimas leva também a rever a justiça dos investimentos em formação e os que são exigidos das famílias. Enquanto os cursos reservados aos melhores alunos são geralmente mais caros e de melhor qualidade que os dos outros - sem contar que as famílias desses alunos também "investem" muito mais nos estudos de seus filhos - seria necessário mudar de perspectiva, o que nos remete ao ponto anterior, o de uma dose de discriminação positiva. A rejeição dessa concepção da justiça continua, no entanto, muito viva entre os que denunciam a diminuição do nível de ensino e, portanto, do prestígio de sua função. Ela se apóia também em 
uma confiança talvez excessiva na qualidade das elites egressas da competição baseada no mérito. Mas será que o preço humano e econômico do subinvestimento nas categorias menos qualificadas é conhecido'?

\section{UMA ESCOLA EFICAZ}

Por que a eficácia social da escola é um problema de justiça? A escola de massas visa a oferecer diplomas a todos os alunos. Pode-se então considerar que esses diplomas tenham um valor utilitário, porque eles fixam o nível e as oportunidades de emprego a que os indivíduos podem pretender. Considerar os diplomas como bens dotados de certa utilidade não diminui em nada sua dimensão cultural. Umas das grandes causas da injustiça provém do fato de que determinados diplomas têm grande utilidade, ao passo que outros não têm nenhuma, numa escola de massas onde todos - ou quase todos - obtêm diploma. Evidentemente, seria uma ilusão imaginar que todos os diplomas têm a mesma utilidade, mas é escandaloso observar que certos diplomas não têm quase nenhuma utilidade, especialmente os que provêm de cursos de formação geral mais fraca, que não oferecem nem uma profissão, nem um nível de qualificação capaz de fazer diferença no mercado de trabalho. Com muita freqüência, esses cursos "vendem" algum tipo de ilusão e certos trabalhos sociológicos já mostraram que estudantes que os freqüentam descobrem tardiamente e com muita amargura que caíram numa "cilada".

Os vínculos entre formação e emprego são, obviamente, extremamente complexos e dependem essencialmente da situação do mercado de trabaIho e da demografia; não seria possível acusar a escola de estar na origem do desemprego dos jovens. Mas isso também não significa que a escola seja totalmente "inocente" a respeito. Diversos cursos secundários e superiores funcionam como verdadeiras "arapucas" quando desvinculados do emprego. De modo geral, os estudantes são encaminhados para esses cursos de maneira "negativa", por falta de opção, e, com freqüência, não chegam ao fim do per-

I De modo geral, não abordo aqui o problema da justiça em termos econômicos, pois haveria muito a dizer sobre a questão de se saber quem ganha e quem perde. É justo que aqueles que fazem estudos que lhes trarão os maiores benefícios pessoais por causa do valor dos diplomas adquiridos não os paguem, quando com freqüência se situam nas categorias mais privilegiadas, o que significa que são sustentados por todos os outros, aqueles para os quais a escola não garante o mínimo? Eis aí uma pergunta não muito conveniente de se fazer, ainda que seja essencial numa escola que se pretenda justa. 
curso que é muito seletivo, em razão do reduzido número de empregos abertos para as respectivas áreas. Pode-se até mesmo pensar que muitas trajetórias escolares funcionaram como alternativas às filas de espera dos desempregados e como maneiras de "armazenar" os jovens no ensino.

A questão da adequação da formação e do mercado de trabalho é muitas vezes tratada como uma exigência patronal que faz parte dos projetos "ultraliberais". É verdade que existe um perigo, mas há também uma grande injustiça em deixar os alunos do ensino médio e os estudantes universitários envolveremse em formações desprovidas de utilidade social. Aliás, os que criticam essa ameaça "ultraliberal" não são geralmente os últimos a escolher, para eles mesmos e para seus filhos, as formações mais úteis. A preocupação com a utilidade dos estudos secundários e superiores faz parte, portanto, de uma dimensão da justiça escolar que, como a das competências mínimas, convida a julgar a justiça de um sistema pela maneira como trata os mais fracos. Por exemplo, é justo deixar milhares de estudantes entrarem nos primeiros ciclos universitários de Letras e Ciências Humanas, sabendo que muitos fracassarão e que os "sobreviventes" terão grande dificuldade para converter seu diploma em emprego? Essa pergunta não é "politicamente correta" em nome da recusa de seleção. Mas ela poderia ser ouvida em nome da luta contra uma hipocrisia bastante banal: esses cursos são de fato muito seletivos e participam assim de uma grande injustiça, pois esses estudantes universitários podem aparecer como vítimas de princípios indiscutíveis que os que podem escapar não aplicam a si mesmos: quantos entre nós defendem o livre acesso a certos cursos de massa e ao mesmo tempo colocam seus filhos nos estabelecimentos seletivos e "rentáveis"?

\section{AS ESFERAS DE JUSTIÇA}

Um dos grandes problemas da justiça é o das relações entre as diversas "esferas de justiça". Walzer ( 1997) considera que todos os campos da atividade social, todas as esferas, vêem surgir sistemas de desigualdades. A escola cria suas próprias desigualdades, a economia cria suas próprias desigualdades, a cultura cria suas desigualdades, a política cria suas desigualdades... As desigualdades de cada um desses domínios podem e precisam ser combatidas. Mas há desigualdade e injustiça novas quando as desigualdades produzidas por uma esfera de justiça provocam automaticamente desigualdades em outra esfera. Assim, desi- 
gualdades de renda causam desigualdades na esfera da escola, da cultura, da política, da saúde e também da beleza... Desse ponto de vista, um sistema justo é aquele que assegura uma certa independência entre as diversas esferas. É, aliás, o que tenta garantir o princípio da igualdade de oportunidades "meritocrático" ao tentar proteger das desigualdades de renda, ou ainda os diversos sistemas sociais que garantem acesso ao atendimento de saúde ou ao sistema político, independentemente da renda e da cultura dos indivíduos.

Estamos habituados a pensar a justiça escolar em termos de efeitos das desigualdades econômicas e sociais sobre a carreira dos alunos, a fim de garantir uma certa autonomia da esfera escolar. Mas uma escola justa precisa também se propor o problema inverso, ou seja, o dos efeitos das desigualdades engendradas pela escola sobre as desigualdades sociais. Ora, estas não são poucas. É justo que os bons alunos venham a se beneficiar de rendas e proteções extremamente favoráveis, ao passo que os maus alunos estarão em desvantagem quase definitiva por sua fraqueza? Em outras palavras, é justo que os diplomas exerçam tamanha influência sobre as outras esferas de atividade? É justo que o sucesso num concurso aos vinte anos, ou que o fracasso num exame aos dezoito anos determine também totalmente a carreira dos indivíduos? Será necessário proceder como se a vida parasse aí, como se a atividade profissional fosse apenas conseqüência dos estudos? Quantas pessoas competentes não conseguiram obter reconhecimento profissional porque estavam em desvantagem devido a sua escolaridade, quantos antigos bons alunos foram protegidos por diplomas que funcionavam como castas ou aristocracias de lugares reservados? É justo que uma reprovação no ensino fundamental feche para sempre certas portas porque alguém ficou um ano "atrasado"?

A questão é provocadora na França, pois pensamos freqüentemente que as desigualdades escolares são justas, ao passo que as desigualdades econômicas e sociais não o são. Mas se admitirmos a hipótese de que as desigualdades escolares não são tão mais justas do que as outras, não se poderia abrandar um pouco a influência dos diplomas sobre o desenvolvimento das carreiras sociais dos indivíduos? Nesse campo, uma escola justa não teria a pretensão de fazer a triagem dos indivíduos de maneira tão definitiva; ela permitiria, aos que fracassaram ou saíram, tentar uma nova oportunidade. Hoje a escola de massas está esmagada por seu próprio poder, pela influência sem precedentes que exerce sobre o destino dos indivíduos, o que contribui para torná-la injusta, fazendo com que suas próprias desigualdades tenham menos impacto 
na vida social, da mesma maneira que as desigualdades sociais repercutem menos na escola. Uma escola menos ligada à formação de castas de excelência e um pouco menos estigmatizante para os alunos fracos, teria sem dúvida efeitos sociais menos injustos. Mas como convencer disso um mundo docente egresso de concursos que determinam as carreiras por toda a vida, quase independentemente dos méritos e do trabalho dos indivíduos?

Um sistema mais aberto, com maior mobilidade, que oferecesse duas ou três oportunidades, menos preocupado com a produção de uma elite fechada, seria provavelmente menos injusto porque suas próprias injustiças teriam menos conseqüências sobre o destino dos indivíduos. Isso não significa, evidentemente, que a escola é mais injusta do que a economia, mas é preciso simplesmente lembrar que, quando as desigualdades não se restringem à sua própria esfera de ação, elas aumentam a injustiça geral da sociedade.

\section{COMO TRATAR OS VENCIDOS?}

Uma escola "meritocrática" de massas cria necessariamente "vencidos", alunos fracassados, alunos menos bons e menos dignos. "O sucesso para todos" é um slogan vazio, por contradizer os princípios meritocráticos sobre os quais a escola se funda. Mesmo que o nível geral dos alunos melhorasse muito, o problema continuaria igual, pelo simples fenômeno da elevação do nível a partir do qual se julga a excelência. Assim sendo, a busca de uma escola justa deve suscitar uma nova pergunta: como ela trataria os alunos mais fracos? Reconhece-se uma escola justa pelo fato de que ela trata bem os vencidos, não os humilha, não os fere, preservando sua dignidade e igualdade de princípio com os outros.

Já sublinhei que isso está longe de ser o caso de uma escola puramente meritocrática em que, se considerarmos que a competição é justa, pode-se dizer "azar dos vencidos", pois eles são responsáveis por sua própria infelicidade. Convém lembrar que, hoje em dia, esse é o caso. Não apenas, como vimos, os alunos mais fracos são geralmente menos bem tratados, como também são "coagidos" a se identificarem com seu fracasso ao acumularem anos de dificuldades ocasionadas por orientações que os encaminham para trajetórias escolares indignas. O mais estranho é que, com muita freqüência, essa indignidade escolar, que parece normal para os conselhos de classe, não significa que essas trajetórias sejam ruins ou inúteis, como no caso do ensino 
profissional. Pode-se, porém, considerar justa uma escola que pratica a orientação negativa, que manda os alunos para as formações técnicas e profissionais não em função de suas competências, mas em função de suas incompetências nas únicas disciplinas julgadas dignas e valorizadoras?

Existe uma clara injustiça quando se constata que os filhos das famílias desfavorecidas têm toda chance de ser conduzidos para ocupações não qualificadas e que, no fundo, a escola não é totalmente responsável por essa situação de fato. No entanto, existe uma injustiça ainda maior quando essa reprodução das desigualdades vem acompanhada de uma estigmatização e de uma desvalorização dos indivíduos. É ao mesmo tempo inútil e cruel, é uma injustiça feita aos alunos mais fracos, aos vencidos na competição escolar. É difícil fracassar e ser conduzido para os empregos pouco valorizados mas úteis, é cruel ser desprezado durante esse percurso. Como não "compreender" (o que não quer dizer justificar) a violência de certos alunos, considerados por todos simples delinqüentes, embora sejam também vítimas, ainda que a maioria das propagandas políticas e sindicais os apresente como inimigos, uma vez que sua presença tornou-se perigosa nas salas de aula?

Uma escola justa preservaria melhor a dignidade e a auto-estima dos que não fossem tão bem-sucedidos como se esperava. Isso supõe dois grandes tipos de ação. $\bigcirc$ primeiro exige uma verdadeira revalorização do ensino técnico e profissional e um interesse maior pelos gostos dos alunos e por seus talentos. O segundo tipo de ação é a afirmação do papel educativo da escola. Uma escola de massas confrontada com escolaridades longas e com o acolhimento de toda uma juventude não pode mais apoiar-se na ficção segundo a qual a instrução é suficiente para educar os alunos. Isso só foi possível numa escola reservada aos bons alunos, aos alunos bem-nascidos e aos "adeptos" dos valores da escola. É preciso então perguntar-se em que a escola pode ser um espaço de educação e de cultura na instrução e mais além, nas atividades culturais e esportivas, na organização da própria vida escolar, no atendimento aos alunos fora da classe. Mas, do mesmo modo que a cultura escolar leva freqüentemente à desvalorização do ensino técnico e profissional, ela considera muitas vezes que essa atividade educativa é indigna, reduzida à animação sociocultural, pronta para ser confiada a professores mal pagos e militantes.

Os vencidos serão mais bem tratados quando se pensar que a escola deve educar todos os alunos independentemente de seu desempenho escolar, quando os alunos e suas famílias se associarem à vida da escola, quando os 
alunos forem tratados como sujeitos em evolução e não apenas como alunos engajados em uma competição. Podemos tranqüilizar-nos, isso não convida nem à acomodação nem à demagogia.

Existem diversos critérios, diversos princípios a partir dos quais é possível definir uma escola justa. Um deles parece-me essencial, porque está ao mesmo tempo no cerne de nossa tradição republicana e porque faz parte das estruturas das sociedades democráticas. Trata-se do modelo de escola meritocrática. Esse modelo de competição justa está bem longe de ser plenamente realizado e sem dúvida é preciso trabalhar para aperfeiçoá-lo. Mas é preciso ter consciência dos seus limites e contradições pelo fato de ele anular outras definições de justiça igualmente desejáveis, principalmente quando não nos colocamos do ponto de vista dos alunos menos favorecidos.

É por essa razão que é preciso aprender a defender outros princípios de justiça e a combiná-los com um modelo meritocrático. É necessário introduzir uma dose de discriminação positiva a fim de assegurar maior igualdade de oportunidades. É preciso também garantir o acesso a bens escolares fundamentais, ou, para afirmar de modo mais incisivo, a um mínimo escolar. A escola justa deve também se preocupar com a utilidade dos diplomas. Ao mesmo tempo, e de maneira oposta, ela deve velar para que as desigualdades escolares não produzam, por sua vez, demasiadas desigualdades sociais. Enfim, um sistema competitivo justo, como o da escola meritocrática da igualdade de oportunidades, deve tratar bem os vencidos na competição, mesmo quando se admite que essa competição é justa.

Alguns acharão essas idéias bastante tímidas, porque elas não se limitam a afirmar o ideal de uma igualdade perfeita, aquela de uma escola capaz de tornar bem-sucedidos todos os alunos e de produzir uma sociedade perfeita. Assumo completamente essa timidez, pois ela me parece mais corajosa que as declarações de intenção mais radicais, que não têm nenhuma possibilidade de ser postas em prática.

Os tradutores deste artigo são membros da Cooperativa de Profissionais em Tradução - Unitrad (unitrad@unitrad.com.br). 


\section{REFERÊNCIAS BIBLIOGRÁFICAS}

BARRÈRE, A. Les Lycéens au travail. Paris: PUF, 1997.

BOURDON, R. L'Inégalité des chances: la mobilité sociale dans les sociétés industrielles. Paris: A. Colin, 1973.

BOURDIEU, P.; PASSERON, J-.C. La Reproduction: les fonctions du système d'enseignement. Paris: Minuit, 1970.

BOWLES, S.; GINTIS, H. Schooling in capitalist America: educational reform and the contradictions of economic life. New York: Basic Book, 1977.

DUBET, F. Le Déclin de l'institution. Paris: Seuil, 2002.

L'École des chances. Paris: Seuil, 2004

Les Lycéens. Paris: Seuil, 1991.

DUBET, F.; DURU-BELLAT, M. L'Hypocrisie scolaire. Paris: Seuil, 2000.

DURU-BELLAT, M. Les Inégalités sociales à l'école. Paris: PUF, 2002.

DURU-BELLAT, M.; MINGAT, A. La Constitution des classes de niveau dans les collèges: les effets pervers d'une pratique à visée égalisatrice. Revue Française de Sociologie, n.4, p.759-789, 1997.

FELOUZIS, G. L'Efficacité des enseignants. Paris: PUF, 1997.

FITOUSSI, J-.P. La Démocratie et le marché. Paris: Grasset, 2004.

JENCKS, C. L'Inégalité, influence de la famille et de l'école en Amérique. Paris: PUF, 1979. LELIĖVRE, C. L'École obligatoire: pour quoi faire. Paris: Retz, 2004.

MAURICE, M.; SELLIER, F.; SYLVESTRE, J.-J. Politiques d'éducation et organisation industrielle en France et en Allemagne. Paris: PUF, 1982.

MERLE, P. Le Concept de démocratisation de l'institution scolaire. Population, v. 55, n. I, p. 15-50, 2000.

PROST, A. L'Enseignement s'est-il démocratisé? Paris: PUF, 1986. Les travaux désormais classiques de C. Baudelot, R. Establet: I'école capitaliste en France.

RAWLS, J. Théorie de la justice. Paris: Seuil, 1987. 
SEN, A. Repenser l'égalité. Paris: Seuil, 2000

WALZER, M. Sphères de justice. Paris: Seuil, 1997.

WILSON, W. J. The Bridge over the racial divide: rising inequality and coalition politics. Berkeley: University of California Press, 1999.

YOUNG, M. The Rise of meritocracy. Harmondworth: Penguin, 1958.

Recebido em: agosto 2004

Aprovado para publicação em: agosto 2004 